\title{
Extinction of differential reward magnitude discrimination in a discrete bar-pressing situation'
}

JOHN W. DAVENPORT and CHARLES F. FLAHERTY, 2 Regional Primate Research Center, University of Wisconsin, Madison, Wis. 53706

Two groups of rats distinguished by the number of bar-presses required to complete a trial (FR 1 or FR 5) were given acquisition, extinction, and reacquisition in an instrumental discrimination involving differential reward magnitude (five pellets vs one pellet). The FR 5 group displayed better discrimination and extinguished faster than the FR 1 group. A "reversed magnitude-extinction effect" was found in that the usual between-groups finding of an inverse relation between resistance to extinction and acquisition reward magnitude failed to appear, i.e., five-pellet start speeds of both groups remained above one-pellet speeds throughout extinction and there was a nonsignificant tendency for relative extinction rates of start speeds to be faster under one-pellet than five-pellet cues.

In this report we present further data on the within-Ss effects of amount of reinforcement in a study of the acquisition, extinction, and reacquisition of an instrumental discrimination based on differential magnitude of reinforcement. With the exception of MacKinnon (1967), previous studies of this type of discrimination (Bower, 1961; Goldstein \& Spence, 1963; Ludvigson \& Gay, 1966, 1967) have not provided information on extinction following differentialmagnitude discrimination; this is of particular interest in view of the fact that a number of experiments (e.g., Hulse, 1958; Wagner, 1961) have shown more rapid extinction following large than small reward in between-groups manipulations of reward magnitude. In MacKinnon's case, all groups were extinguished in the presence of only one of the two stimuli constituting their original discrimination conditions. In the present study, extinction to both stimuli was examined within each $S$.

Using a discrete-trials retractable lever situation, we have also studied the effects of different response requirements in the definition of a trial, in the manner investigated by Gonzalez, Bainbridge, \& Bitterman (1966), as part of a continuing quest for adequate automated analogues of the manual black-white runway situation. Throughout acquisition, extinction, and reacquisition, a group of rats permitted only one bar-press per trial (FR 1) was compared with a second group in which five presses per trial (FR 5) were required.

\section{SUBJECTS}

The subjects (Ss) were 16 naive male albino rats of the Holtzman strain, approximately 120 days old at the beginning of pretraining. Throughout the experiment they were maintained at $80 \%$ of free-feeding weight. APPARATUS

The apparatus consisted of two identical Gerbrands Model C test chambers, details of which are described elsewhere (Flaherty \& Davenport, in press). Each chamber was equipped with a Lehigh Valley retractable lever, a white cue light over the lever, a house light, a recessed food cup, and a 45-mg pellet dispenser.

\section{PROCEDURE}

Pretraining consisted of magazine training (Day 1,60 pellets in $30 \mathrm{~min}$ ), free-operant lever training (Day 2, 20 reinforced responses), and discretetrial lever training (Days 3 and 4). On Day 3 the Ss were randomly divided into FR 1 and FR 5 groups and given 20 trials. Trial onset was signaled by insertion of the lever and onset of the house light. When $\mathbf{S}$ completed its response the lever was retracted and a single-pellet reward was delivered; the house light remained on for $10 \mathrm{sec}$ after the reward delivery. The FR 1 group was permitted only one lever response per trial throughout the 20 trials of Day 3 and an additional 20 trials on Day 4. The FR 5 group was given five trials on FR 2, five on FR 3, and 10 on the final FR 5 schedule on Day 3, and an additional 20 FR 5 trials on Day 4.

Discrimination training began on Day 5. Half of the 20 trials given each day were reinforced with five pellets and half with one pellet. The discriminative stimuli were the click of a relay pulsed at 10 per sec and the flashing, at 10 per sec, of the white cue light. The pairing of these stimuli with the reward magnitudes was counterbalanced and confounded with boxes. Trial sequences within sessions followed four different Gellermann series. Throughout the experiment the Ss were run two at a time with simultaneous trial onsets in the two boxes. Both the discriminative cue and the house light began at trial onset and remained on for $10 \mathrm{sec}$ after reward delivery. The timing of the intertrial interval, a VI $30 \mathrm{sec}$, did not begin until the trial in both boxes had timed out.

Twenty-two 20-trial discrimination sessions were given, after which extinction trials were administered in eight 20-trial sessions. Extinction trial conditions were the same as in discrimination except for the omission of reinforcement, i.e., response completion on each trial produced only a 10-sec nonreinforced period in which the house light and the five- or one-pellet cue remained on and the lever was retracted.

Following extinction the Ss received eight 20-trial reacquisition sessions. In this phase trials with the five- or one-pellet cues were given in the same sequences as in acquisition but responses were reinforced by five pellets on all trials, as was done by Logan $(1960$, p. 188) in a test of historical effects of acquisition conditions in a between-groups reward magnitude study.

Latency of the first lever response on each trial was recorded on a print-out counter and converted to start speed (100 times reciprocal latency). For the FR 5 group the additional measures of time to complete the five responses (ratio time) and the reciprocal of this (ratio speed) were also taken.

\section{RESULTS}

Start speed curves for the two groups over the entire course of the experiment are presented in Fig. 1. Clear evidence of discrimination was found in both groups. The suggestion of somewhat greater start speed differences between five- and one-pellet trials in the FR 5 group during acquisition was not
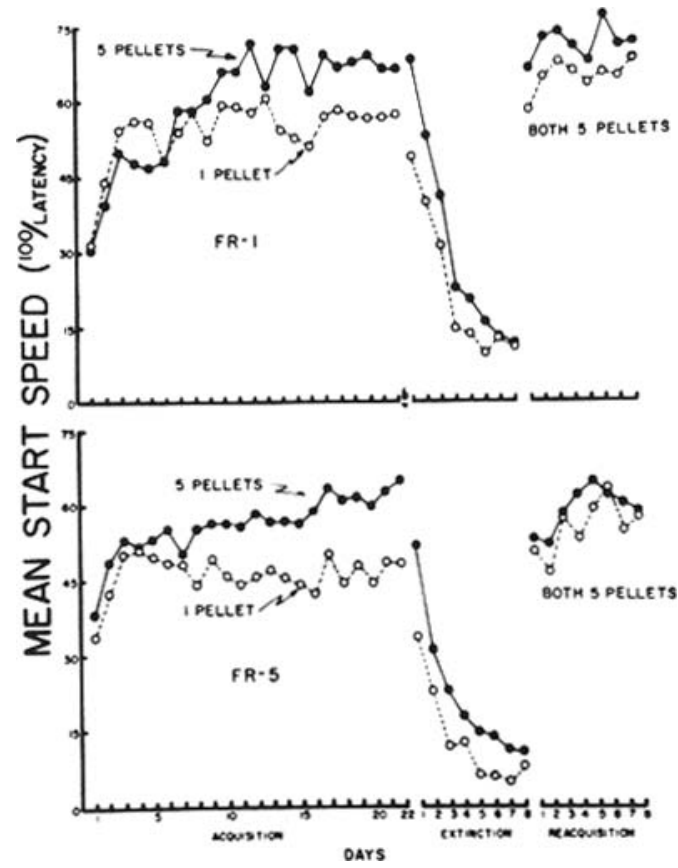

Fig. 1. Mean start speed for the two groups over the acquisition, extinction, and reacquisition phases. 


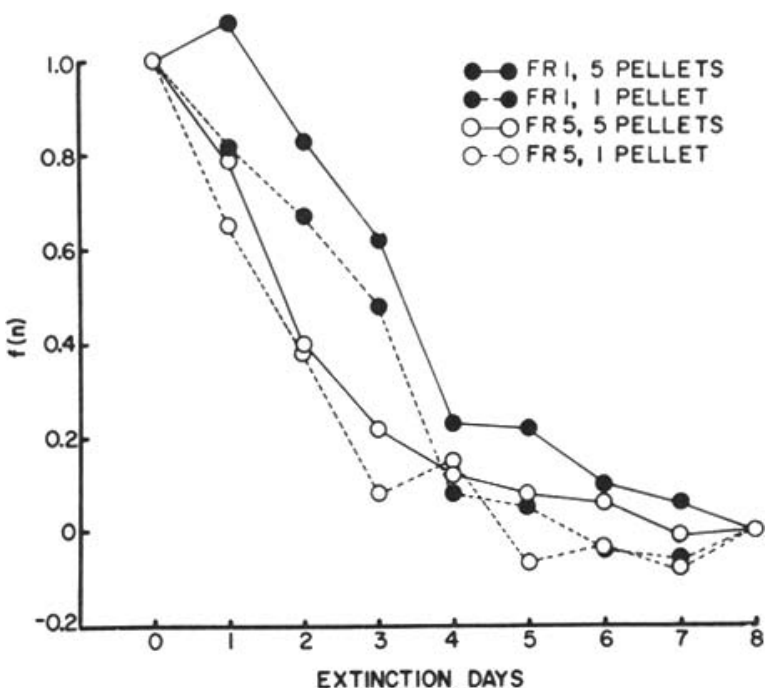

Fig. 2. Kelative rate of extinction of start speed in terms of mean $f(n)$ value.

supported statistically, but in terms of original latencies significantly better discrimination by the FR 5 group was found $(\mathrm{F}=9.36, \mathrm{df}=1 / 12, \mathrm{p}<.01)$. Overall start speed in acquisition tended to be higher in the FR 1 group $(F=2.37, \mathrm{df}=2 / 252$, $\mathrm{p}<.01)$.

In extinction there was no indication of a crossover of.the five- and one-pellet start speed curves and start speeds to five-pellet cues were in general higher than to one-pellet cues $(F=6.48, \mathrm{df}=7 / 84, \mathrm{p}<.01$, for interaction between prior reward magnitude and days). Ratio speeds of the FR 5 group were similar to start speed data in showing faster responding under five- than one-pellet cues in extinction. Start speeds of the FR 1 group were higher than the FR 5 group's in extinction ( $F=6.18, \mathrm{df}=7 / 84, \mathrm{p}<.01$, interaction of ratio length and days).

Since these differences largely reflected differences at the end of acquisition, relative rate of extinction was examined by applying Anderson's (1963) shape function conversion to the start speeds (Fig. 2). In terms of $f(n)$ values extinction was nonsignificantly faster under one-pellet than five-pellet cues $(F=3.65, \mathrm{df}=1 / 12, \mathrm{p}<.10)$ and significantly faster in the FR 5 group than in the $F R 1$ group $(F=13.14, \mathrm{df}=1 / 12$, $p<.01)$; there was no significant interaction between ratio length and prior reward magnitude $(F<1.0)$.

In reacquisition both groups showed small but statistically significant start speed differences between five- and one-pelletcue trials $(F=12.10$, $\mathrm{df}=1 / 12, \mathrm{p}<.01)$, indicating that historical effects of differing reward magnitude conditions can survive an extinction period and be revealed in retraining under constant-reward conditions in a within-Ss manipulation.

\section{DISCUSSION}

The major indication here was that differential-magnitude discrimination of the instrumental (successive) type generates differential response tendencies to large- and small-reward cues that are at least equal in terms of relative resistance to extinction and opposite to what has usually been found in extinction following between-groups variations of reward magnitude (e.g., Hulse, 1958; Wagner, 1961) in terms of unconverted extinction measures. This paradoxical "reversed magnitude-extinction effect" may be compared with the frequently-reported (see Amsel, 1967) failure to obtain the partial reinforcement extinction effect in within-Ss manipulations. Without further elaboration, however, neither Amsel frustration theory nor its close competitor, Capaldi's (1967) sequential hypothesis, seems ready for complete theoretical explication of these paradoxes, particularly in lever-pressing situations. At the empirical level, we begin to wonder whether within-Ss studies of other reinforcement variables, e.g., delay and temporal distribution of reinforcement, will reveal "reversed differential reinforcement extinction effects" as a general phenomenon.

The findings that discrimination appeared more clearly in the FR 5 group and that this group extinguished more rapidly than the FR 1 group are consistent with those of Gonzalez et al (1966) in the sense that adding a small fixed ratio in the discrete bar-pressing task seems to increase sensitivity to inhibitory effects. Whether this is due to greater effort required, an increase in the probability of competing responses interfering with the measured response, increased exposure to discriminative cues during the execution of the measured response, or some other factor, remains to be seen in future research.

\section{REFERENCES}

AMSEL, A. Partial reinforcement effects on vigor and persistence. In $K$. W. Spence and J. T. Spence (Eds.), The psychology of learning and motivation: Advances in research and theory, Vol. 1. New York: Academic Press, 1967. Pp. 1-65.

ANDERSON, N. H. Comparison of different populations: Resistance to extinction and transfer. Psychological Review, 1963, 70, 162-179.

BOWER, G, H. A contrast effect in differential conditioning. Journal of Experimental Psychology, 1961, 62, 196-199.

CAPALDI, E. J. A sequential hypothesis of instrumental learning. In $\mathrm{K}$. W. Spence and J. T. Spence (Eds.), The psychology of learning and motivation: Advances in research and theory, Vol. 1. New York: Academic Press, 1967. Pp. 67-156.

FLAHERTY, C. F., \& DAVENPORT, J. W. Noncontingent pretraining in instrumental discrimination between amounts of reinforcement. Journal of Comparative \& Phy siological Psychology, in press.

GOLDSTEIN, H., \& SPENCE, K. W. Performance in differential conditioning as a function of variation in magnitude of reward. Journal of Experimental Psychology, 1963, 65, 86-93.

GONZALEZ, R. C., BAINBRIDGE, P., \& BITTERMAN, M. E. Discrete-trials lever pressing in the rat as a function of pattern of reinforcement, effortfulness of response, and amount of reward. Journal of Comparative \& Physiological Psychology, 1966, 61, $110-122$.

HULSE, S. H. Amount and percentage of reinforcement and duration of goal confinement in conditioning and extinction. Journal of Experimental Psychology, 1958, 56, 48-57.

LOGAN, F. A. Incentive. New Haven: Yale University Press, 1960. P. 188.

LUDVIGSON, H. W., \& GAY, R. A. An investigation of conditions determining contrast effects in differential reward conditioning. Journal of Experimental Psychology, 1967, 75, 3742.

LUDVIGSON, H. W., \& GAY, S. E. Differential reward conditioning: Scontrast as a function of the magnitude of St. Psychonomic Science. 1966, 5, 289-290.

MacKINNON, J. R. Interactive effects of the two rewards in a differential magnitude of reward discrimination. Journal of Experimental Psychology, 1967, 75, 329-338.

WAGNER, A. R. Effects of amount and percentage of reinforcement and number of acquisition trials on conditioning and extinction. Journal of Experimental Psychology, 1961, 62, 234-242.

$$
\text { NOTES }
$$

1. This research was supported by Grant FR-00167 from the National Institutes of Health.

2. Now at Department of Psychology, Rutgers, The State University, New Brunswick, N. J. 